\title{
Are there more exotropes than esotropes in Hong Kong?
}

\section{S R Lambert}

\section{Yes, but are Asian children more likely to be exotropic than white children?}

d

$\mathrm{t}$ is well known that there are marked differences in the prevalence of certain ocular disorders among various ethnic groups. These differences probably reflect the unique genetic make-up of these ethnic groups coupled with a variety of environmental influences. Ethnic variations are particularly marked for the prevalence of myopia and hyperopia. While population based studies from the United States ${ }^{12}$ and Australia ${ }^{3}$ have reported a prevalence of myopia ranging from $15-26 \%$ in adults, the prevalence has been reported to be significantly higher in Singapore (35\%). Asian countries in particular have also been experiencing a dramatic increase in the prevalence of myopia. For example, $82 \%$ of all ethnic Chinese Singapore military recruits screened between July 1996 and June 1997 were myopic. ${ }^{\circ}$

In this issue of the $B J O(\mathrm{p} 854)$, Yu and coworkers report that the incidence of exotropia is twice as common as esotropia in the strabismus clinic at the Hong Kong Eye Hospital, whereas studies based in Europe and North America have reported a much higher percentage of esotropes than exotropes. In addition, $\mathrm{Yu}$ and coworkers report that the ratio of exotropia/esotropia in Hong Kong has increased dramatically over the past decade. How can these differences be explained?

Firstly, the increased incidence of exotropia in Hong Kong may reflect a difference in the prevalence of certain refractive errors among Chinese children that are risk factors for the development of various types of strabismus. The Refractive Error Study in Children, a population based study sponsored by the World Health Organization, elucidated some important differences between the refractive errors of Asian and white children. $^{7-10}$ The study compared the prevalence of refractive errors among children 5-15 years of age in China, Nepal, and Chile. Interestingly, the prevalence of myopia did not differ markedly between 5 year olds in these countries (China $<1 \%$; Nepal $<2 \%$; Chile $3.5 \%)$; however, the prevalence of myopia was much higher in Chinese 15 year olds (males 36.7\%; females 55.0\%) compared to 15 year olds in Nepal (males 2\%; females $1 \%$ ) and Chile (males $20 \%$; females $15 \%)$. Conversely, the incidence of moderate or high hyperopia ( $>2$ D) in children 5-7 years of age was much higher in Chile (Nepal 1.1\%; China 8.5\%; Chile $21.6 \%$ ). The higher percentage of moderate and high hyperopes in Chile would suggest that white populations are more likely to be hyperopic than Asian populations. Since a close linkage between accommodative esotropia and hyperopia has been established, ${ }^{11-13}$ it is not surprising that a higher percentage of white than Asian patients would become esotropic, particularly since the majority of esotropic children have accommodative esotropia. ${ }^{14}$ It is less clear if the increasing incidence of myopia in Asian children can account for the increasing ratio of exotropes to esotropes in Hong Kong.

\section{Esotropia is probably higher in white than in Asian children because white children are more likely to be moderate or high hyperopes}

While a linkage between myopia and intermittent exotropia in children may exist, the linkage is largely inferential. Kushner ${ }^{15}$ reported a mean initial refractive error of 0.0 (SD 1.40) D in a group of children with intermittent exotropia when 4.4 years of age, whereas 4 year old non-strabismic children in Boston had a mean refractive error of $+1.13(0.85) \mathrm{D}$, and 5 year old children in Chile a mean refractive error of +1.3 D. ${ }^{10}{ }^{16}$ In addition to being less hyperopic when initially diagnosed, intermittent exotropes tend to become more myopic over time compared to age matched controls. After a 5 year follow up, the intermittent exotropes in Kushner's ${ }^{15}$ study had a mean refractive error of -1.40 (2.80) D and after a 10 year follow up a mean refractive error of -2.41 (2.20) D, whereas boys in Chile had a mean refractive error of $+1.1 \mathrm{D}$ when 10 years of age and $+0.2 \mathrm{D}$ when 15 years of age. ${ }^{10}$ Since most children with intermittent exotropia became symptomatic by the age of 5 years, the low incidence of myopia even in Chinese children when 5 years of age, would argue against the increasing incidence of myopia in older children being a significant factor accounting for the increasing incidence of exotropia in Hong Kong. More likely, a decreasing incidence of moderate or high hyperopic refractive errors has resulted in fewer patients developing accommodative esotropia, thereby increasing the ratio of exotropes to esotropes. This may also explain why $\mathrm{Yu}$ and coworkers found an increasing proportion of nonaccommodative to accommodative esotropes in Hong Kong over the past decade.

A second possible factor to explain the higher ratio of exotropes to esotropes in Hong Kong relative to the North American and European studies cited may be the demographics of the patients studied. Yu and coworkers included in their study all patients 19 years of age or younger presenting to their clinic with strabismus, whereas the studies cited from North America and Europe included only patients who were 7 years of age or younger. ${ }^{17-21}$ Since two of the most common types of esotropia (accommodative and infantile) almost never present after the age of 7 years, whereas both intermittent and sensory exotropia may develop in older children, there would be an inherent bias in Yu's study to have an increased ratio of exotropes to esotropes. However, it seems unlikely that this can fully account for the high ratio of exotropes to esotropes in Yu's study since Ing and Pang ${ }^{22}$ have reported an increased prevalence of exotropes compared to esotropes in Asian children 7 years of age or younger. ${ }^{22}$

In conclusion, esotropia is probably higher in white than in Asian children because white children are more likely to be moderate or high hyperopes. It is less clear if the prevalence of exotropia is more common in Asian than in white children. Careful population based studies would be the best means of elucidating true differences in the prevalence of different forms of strabismus among Asian and white children. While the recently completed Refractive Error Study in Children included an ocular motility evaluation, only cursory data are provided which do not allow a meaningful comparison to be made between Asian and white children. ${ }^{7-10}$ So are there more exotropes than esotropes in Hong Kong? Yes. But are Asian children more likely to be exotropic than white children? We'll have to wait to find out.

\section{ACKNOWLEDGEMENT}

Supported in part by NIH Core Grant P30 EY06360 and Research to Prevent Blindness, Inc, New York, USA

Br J Ophthalmol 2002;86:835-836 


Author's affiliations
REFERENCES
1 Katz J, Tielsch JM, Sommer A. Prevalence and
risk factors for refractive errors in an adult
inner city population. Invest Ophthalmol Vis
Sci 1997;38:334-40.
2 Wang Q, Klein BE, Klein R, et al. Refractive
status in the Beaver Dam Eye Study. Invest
Ophthalmol Vis Sci 1994;35:4344-7.
3 Wensor M, McCarty CA, Taylor HR.
Prevalence and risk factors of myopia in
Victoria, Australia. Arch Ophthalmol
$1999 ; 116: 658-63$.
4 Attebo K, Ivers RQ, Mitchell P. Refractive
errors in an older population: the Blue
Mountains Eye Study. Ophthalmology
1999;106:1066-72.
5 Wong TY, Foster PJ, Hee J, et al. Prevalence
and risk factors for refractive errors in adult
Chinese in Singapore. Invest Ophthalmol Vis
Sci 2000;41:2486-94.
6 Wu H-M, Seet B, Yap EP-H, Saw S-M, et al.
Does education explain ethnic differences in
myopia prevalence? A population-based study
of young adult males in Singapore. Optom Vis
Sci 2001; $78: 234-9$.

7 Negrel AD, Maul E, Pokharel GP, et al. Refractive error study in children: sampling an measurement methods for a multi-country survey. Am J Ophthalmol 2000;1 29:42 1-6.

8 Zhao J, Pan X, Sui R, et al. Refractive error study in children: results from Shunyi District,
China. Am J Ophthalmol 2000;1 29:427-35

9 Pokharel GP, Negrel AD, Munoz SR, et al. Refractive error study in children: results from Mechi Zone, Nepal. Am J Ophthalmol 2000; 129:436-44

10 Maul E, Barroso S, Munoz SR, et al. Refractive error study in children: results from La Florida, Chile. Am J Ophthalmol 2000; 129:445-54

11 Worth C. The aetiology of convergent squint In: Squint: its causes, pathology, and treatment. 3rd ed. London: John Bale, Sons \& Danielsson Ltd, 1906:48-62.

12 Lyle TK. Theories as to the causation of accommodational squint. In: Worth and Chavassee's squint. The binocular reflexes and the treatment of strabismus. Philadelphia: The Blakiston Company, 1950:129-46.

13 Parks MM. Abnormal accommodative convergence in squint. Arch Ophthalmol 1958;59:364-80.

14 Mohney BG. Common forms of childhood esotropia. Ophthalmology 2001;108:805-9.
15 Kushner BJ. Does overcorrecting minus lens therapy for intermittent exotropia cause myopia? Arch Ophthalmol 1999:117:638-42.

16 Mayer DL, Hansen RM, Moore BD, et al. Cycloplegic refractions in healthy children aged 1 through 48 months. Arch Ophthalmol $2001 ; 119: 1625-8$

17 Rantanen A, Tommila V. Prevalence of stravismus in Finland. Acta Ophthalmol 1971:49:506-9.

18 Graham PA. Epidemiology of strabismus. Br J Ophthalmol 1974;54:224-31.

19 Kornder LD, Nursey JN, Pratt-Johnson JA, et al. Detection of manifest strabismus in young children. 2. A retrospective study. Am J Ophthalmol 1974;77:211-14

20 Friedman Z, Neumann E, Hyams SW Ophthalmic screening of 38,000 children, age 1 to $2 \frac{1}{2}$ years, in child welfare clinics. $J$ Paediatr Ophthalmol Strabismus 1980;17:261-7.

21 Schlossman A, Boruchoff SA. Correlation between physiologic and clinical aspects of exotropia. Am J Ophthalmol 1955;40:53-64

22 Ing MR, Pang SW. The racial distribution of strabismus. A statistical study. Hawaii MedJ 1974;33:22-3.

\section{A few remarks about glaucoma}

\section{A Wegner}

\section{New incidence and prevalence studies required}

W eber designed the first applanation tonometer in 1867 Goldmann constructed the modern applanation tonometer in 1954, but only 27 years ago Ehlers et al presented their study that showed the correlation between central corneal thickness (CCT) and intraocular pressure (IOP) applanation tonometric measurement. The number of publications about central corneal thickness measurements has risen exponentially over the past few years, ${ }^{2}$ but do we use this information? The implementation of this inverse correlation between CCT and IOP on the glaucoma/ocular hypertension (OHT) patients has a great impact on our knowledge, understanding, classification, and treatment of glaucoma. This means that many OHT patients should be reclassified as normal; from 30\% as Argus $^{3}$ found or even up to $65 \%$ according to Herndon et al. ${ }^{4}$ Of the normal tension glaucoma (NTG) patients a similar proportion can be reclassified; $31 \%$ according to Copt et al. But this is only the beginning. All the data concerning prevalence of OHT, NTG, and primary open angle glaucoma (POAG) must be revised as well as all the data concerning natural history and typical morphological changes of OHT be doubted. and NTG. One of the most important consequences should be that corneal pachymetry is a must when conducting a study with OHT or NTG patients, otherwise the population study is false and the results are not valid. Nevertheless, most publications dealing with OHT and NTG patients do not put these criteria to use, and we continue to gather inaccurate information. The Ocular Hypertension Treatment Study ${ }^{6}$ has to readjust its eligibility assessmentinclude CCT pachymetry-otherwise the results of this important study will

Visual field examination and interpretation is one of the pillars of ophthalmological diagnoses. Bengtsson et $a l^{7}$ introduced in 1997 the Swedish interactive threshold algorithm (SITA), a static perimetry operating system/ software package. SITA standard presents a reduced number of stimuli by an average of $25 \%$ and test time reduction up to $50 \% .^{7-9}$ SITA has greater patient acceptance than full threshold strategy. ${ }^{10}{ }^{11}$ The mean sensitivity is about $\mathrm{l} \mathrm{dB}$ higher than in a full threshold program and the age dependent decrease of mean sensitivity is $25 \%$ smaller. ${ }^{12}{ }^{13}$ The intersubject variance is $30 \%$ smaller. $^{913}$ In glaucoma patients the SITA standard shows a larger number of significantly depressed points. ${ }^{14}$ Perimetry is still the gold standard for most ophthalmologists for glaucoma monitoring. Should we be satisfied with a blurred presentation of visual field instead of a clear and sharp presentation only because of greater patient acceptance? All the deviations of sensitivity in comparison with full threshold strategy are the result of the algorithm behind SITA, as well as the lower intersubject variance that is flattened by an algorithm, and not because of shorter examination time. It can be deduced, if we look at a similar strategy, that tendency oriented perimetry (TOP), has similar drawbacks. ${ }^{15} 16$

\section{What we are measuring is the ability of a method to detect the patients who were classified as having glaucoma with another method ... but not the overall ability to detect the pathology}

In the Hippocratic aphorisms the term glaucoma is first mentioned as a diagnosis. But, still there is no agreement over the definition of glaucoma or what are the criteria to diagnose glaucoma. A review of 182 articles about POAG published in 1980, 1985, 1990, and 1995 in the American Journal of Ophthalmology, Ophthalmology, and Archives of Ophthalmology showed that only $66 \%$ included a definition of POAG. ${ }^{17}$ Among these, there are various combinations of optic disc visual field criteria and IOP to define 
POAG. In the population based Rotterdam Study, different commonly used criteria for the diagnosis of POAG resulted in prevalence figures ranging from $0.1 \%$ to $1.2 \%{ }^{18}$ Millions of people all over the world are treated for glaucoma-in the United States more than one million. Bohn et al ${ }^{19}$ have shown that in almost half $(44.7 \%)$ of 544 patients who were treated for POAG, the only parameter used for diagnosis was IOP. As long as there are no accepted criteria for glaucoma diagnosis the correct time for first medical intervention is unclear and studies are difficult to compare. The same problem arises as we try to compare various screening methods and calculate their sensitivity and specificity. Furthermore, no method can detect all glaucoma cases..$^{20-23}$ The sensitivity and specificity is falsified, as some people who have glaucoma and who are detected with one method will not be detected by another method and vice versa. Actually, what we are measuring is the ability of a method to detect the patients who were classified as having glaucoma with another method, which is inaccurate in itself, but not the overall ability to detect the pathology. To minimise those problems a classification and definition system should be agreed upon.

A final remark, over the years it has been suggested that the new diagnostic tools enable us to detect glaucoma much earlier. Is it not time to implement these methods and to do new population based incidence and prevalence studies of glaucoma with the new diagnostic devices? I would expect a shift to the left of the age distribution. Glaucoma is ready for an update.

Br J Ophthalmol 2002;0:836-837

\section{Author's affiliations}

A Wegner, Glaucoma Service, Department of Ophthalmology, Klinikum rechts der Isar, Munich Technical University, 22 Ismaninger Strasse, 81679 Munich, Germany;

A.Wegner@|rz.tum.de

\section{REFERENCES}

1 Ehlers N, Bramsen T, Sperling S. Applanation tonometry and central corneal thickness. Acta Ophthalmol Copenh 1975;53:34-43.

2 Doughty MJ, Zaman ML. Human corneal thickness and its impact on intraocular pressure measures: a review and meta-analysis approach. Surv Ophthalmol 2000:44:367-408.

3 Argus WA. Ocular hypertension and central corneal thickness. Ophthalmology 1995; 102:1810-2.

4 Herndon LW, Choudhri SA, Cox T, et al. Central corneal thickness in normal, glaucomatous, and ocular hypertensive eyes. Arch Ophthalmol 1997;1 15:1137-41.

5 Copt RP, Thomas R, Mermoud A. Corneal thickness in ocular hypertension, primary open-angle glaucoma, and normal tension glaucoma. Arch Ophthalmol 1999;117:14-16.

6 Gordon MO, Kass MA. The Ocular Hypertension Treatment Study: design and baseline description of the participants. Arch Ophthalmol 1999;117:573-83.

7 Bengtsson B, Olsson J, Heijl A, et al. A new generation of algorithms for computerized threshold perimetry, SITA. Acta Ophthalmol Scand 1997:75:368-75.

8 Bengtsson B, Heiil A, Olsson J. Evaluation of a new threshold visual field strategy, SITA, in normal subjects. Swedish Interactive Thresholding Algorithm. Acta Ophthalmol Scand $1998 ; 76: 165-9$

9 Bengtsson B, Heijl A. Evaluation of a new perimetric threshold strategy, SITA, in patients with manifest and suspect glaucoma. Acta Ophthalmol Scand 1998;76:268-72.

10 Shirato S, Inoue R, Fukushima K, et al. Clinical evaluation of SITA: a new family of perimetric testing strategies. Graefes Arch Clin Exp Ophthalmol 1999:237:29-34.

11 Sharma AK, Goldberg I, Graham SL, et al. Comparison of the Humphrey Swedish Interactive Thresholding Algorithm (SITA) and full threshold strategies. J Glaucoma 2000:9:20-7.
12 Wild JM, Pacey IE, Hancock SA, et al Between-algorithm, between-individual differences in normal perimetric sensitivity: full threshold, FASTPAC, and SITA. Swedish Interactive Threshold algorithm. Invest Ophthalmol Vis Sci 1999:40:1152-61.

13 Bengtsson B, Heijl A. Inter-subject variability and normal limits of the SITA Standard, SITA Fast, and the Humphrey Full Threshold computerized perimetry strategies, SITA STATPAC. Acta Ophthalmol Scand 1999;77:125-9.

14 Bengtsson B, Heiil A. Comparing significance and magnitude of glaucomatous visual field defects using the SITA and full threshold strategies. Acta Ophthalmol Scand 1999;77:143-6.

15 Morales J, Weitzman ML, Gonzalez de la Rosa M. Comparison between tendency-oriented perimetry (TOP) and Octopus threshold perimetry. Ophthalmology 2000; 107: 134-42

16 Lachkar Y, Barrault O, Lefrancois A, et al. Rapid tendency oriented perimeter (TOP) with the Octopus visual field analyzer. $J \mathrm{Fr}$ Ophtalmol 1998;21:180-4.

17 Bathija R, Gupta N, Zangwill L, et al. Changing definition of glaucoma. J Glaucoma 1998;7:165-9

18 Wolfs RC, Borger PH, Ramrattan RS, et al. Changing views on open-angle glaucoma: definitions and prevalences - the Rotterdam Study. Invest Ophthalmol Vis $\mathrm{Sci}$ 2000:41:3309-21

19 Bohn RL, Gurwitz JH, Yeomans SM, et al. Which patients are treated for glaucoma? An observational analysis. J Glaucoma 2000; 9:38-44.

20 Zangwill LM, Bowd C, Berry CC, et al. Discriminating between normal and glaucomatous eyes using the Heidelberg retina tomograph, GDx nerve fiber analyzer, and optical coherence tomograph. Arch Ophthalmol 2001:119:985-93.

21 Teesalu P, Airaksinen PJ, Tuulonen A. Blue-on-yellow visual field and retinal nerve fiber layer in ocular hypertension and glaucoma. Ophthalmology 1998;105:2077-81.

22 Reyes RD, Tomita G, Kitazawa Y. Retinal nerve fiber layer thickness within the area of apparently normal visual field in normal-tension glaucoma with hemifield defect. J Glaucoma 1998;7:329-35.

23 Kwon YH, Hong S, Honkanen RA et al. Correlation of automated visual field parameters and peripapillary nerve fiber layer thickness as measured by scanning laser polarimetry. J Glaucoma 2000;9:281-8. 